\title{
ESTUDOS SOBRE A FAUNA DE SARCOPHAGIDAE (DIPTERA) DE BELO HORIZONTE - MINAS GERAIS. 1 - LEVANTAMENTO TAXONOMICO E SINANTROPICO
}

\author{
EDELBERTO SANTOS DIAS, * DAVID PEREIRA NEVES ** \\ \& H. DE SOUZA LOPES***
}

Com o objetivo de se conhecer a fauna de Sarcophagidae da regiäo de Belo Horizonte, Minas Gerais, e se obter dados sobre seu comportamento, foram realizadas capturas sistemáticas em três áreas ecologicamente distintas, pelo periodo de um ano (maio de 1980 a abril de 1981).

Para as capturas, foram utilizadas dois tipos de armadilhas apropriadas $e$ cinco tipos de iscas: peixe cru, carcaça de camundongo, visceras de galinha, banana amassada com rapadura e fezes humanas.

Foi capturado um total de 10.097 espécimens, dos quais foram estudados 9.582 exemplares, representados por 25 espécies.

(1963).

$O$ indice de sinantropia foi determinado segundo a metodologia de Nuorteva

Foram obtidos indices variáveis de sinantropia para as 25 espécies analisadas, sendo as mais sinantrópicas Parasarcophaga ruficornis $(I S=+94,7)$ e Bercaea haemorrhoidalis $(I S=+84,3)$, e as mais assinantrópicas Euboettcheria florencioi $(I S=-98,8)$ e Oxysarcodexia augusta $(I S=-96,9)$.

Os dípteros muscóides apresentam grande interesse não só do ponto de vista ecológico, mas também médico-sanitário. Isto se deve ao fato de que estas moscas podem transportar mecanicamente um grande número de organismos patogênicos causadores de doenças humanas e animais. Além disso, existe uma condição patogênica provocada por larvas de determinadas espécies que, através da invasão dos tecidos ou órgãos do homem e outros animais, determinam uma afeç̧ão conhecida como "miŕase".

Estes dípteros apresentam capacidade de adaptação às condiçōes ambientais favoráveis, criadas pelo homem. Esta característica de determinadas moscas é conhecida como sinantropia, e o grau de adaptabilidade mosca-ambiente pode ser medido através do indice de sinantropia (Nuorteva, 1963).

Devido ao pouco conhecimento da fauna destes dípteros em nossa região e sua importância médico-sanitária colocou-se, como propósito de trabalho, o reconhecimento

\footnotetext{
Este trabalho é parte da Tese apresentada no Departamento de Parasitologia da Universidade Federal de Minas Gerais, para obtençāo do grau de Mestre, com auxílio da CAPES, CNPq e FINEP.

- Centro de Pesquisas René Rachou - FIOCRUZ, Caixa Postal 1743, 30000 Belo Horizonte, MG.

** Departamento de Parasitologia do ICB da Universidade Federal de Minas Gerais.

* * Academia Brasileira de Ciências, Rio de Janeiro, RJ.
}

Recebido para publicaçāo em 2 de junho e aceito em 2 de agos to de 1983. 
taxonômico das espécies de sarcofagídeos de Belo Horizonte, Minas Gerais, com seus respectivos indices sinantrópicos, e o estudo quantitativo e qualitativo da incidencia das diferentes espécies em três áreas ecologicamente distintas.

\section{MATERIAL E MÉTODOS}

Para a captura das moscas foram utilizados dois tipos de armadilhas:

Tipo $I$ - constituída por um cilindro de filó branco ligado na sua porção superior a um cone do mesmo material; na parte inferior, existe um quadrado de medeirite medindo $25 / 25 \mathrm{~cm}$ fixado ao cone através de três ganchos eqüidistantes, deixando uma fresta de $2 \mathrm{~cm}$, entre a base do cilindro e a madeira, por onde as moscas podem penetrar.

As iscas variadas (peixe cru, carcaça de camundongo albino, vísceras de galinha, banana amassada com rapadura e fezes humanas), sempre 50 gramas por armadilha, foram colocadas no centro da madeira.

Este tipo de armadilha foi sugerido por Lopes (1980), em comunicação pessoal.

Tipo II - constituída por uma lata de cor preta com oito furos na parte inferior, por onde podem penetrar as moscas. Dentro dela coloca-se um cone de papel aberto nas duas extremidades, e com o vértice voltado para cima. Por fora da lata ajusta-se um saco plástico, cuja remoção permite a coleta das moscas capturadas.

Essa armadilha foi anteriormente utilizada por Ferreira $(1978,1979)$ e Linhares $(1979,1981)$.

Foram utilizadas 10 armadilhas em cada área sendo 5 do tipo I e 5 do tipo II, dispostas em duas filas paralelas (uma fila para cada tipo), sempre distanciadas uma da outra de $1 \mathrm{~m}$ aproximadamente.

Todas as armadilhas estavam expostas ao sol.

As capturas foram realizadas em três áreas ecologicamente distintas: urbana, rural e de mata, durante cinco dias consecutivos por mês, no período de maio de 1980 a abril de 1981.

Área urbana - representada por um quintal de uma residência situada em um bairro (Lagoinha), dentro do perímetro comercial da cidade.

Área rural - representada por um pasto, localizado junto à Escola de Veterinária, dentro do campus da Universidade Federal de Minas Gerais. Nesta área é constante a presença de animais domésticos (bovinos, eqüinos, ovinos) pastando.

Área de mata - representada por uma mata de cerca de 5 ha, constituída por árvores com aproximadamente $10 \mathrm{~m}$ de altura, conservando suas características naturais.

As distâncias entre as áreas são: urbana x rural $-8 \mathrm{~km}$; nural x mata $-3 \mathrm{~km}$; urbana $\mathrm{x}$ mata $-8 \mathrm{~km}$.

As moscas foram sacrificadas em éter ou clorofórmio, no local de captura. No laboratório, o material foi alfinetado, e rotulado, expondo-se a genitália dos machos, de acordo com Lopes (1973).

Procedia-se à determinação, com uso de chave taxonômica (Lopes, 1946, Oxysarcodexia spp), consultas a descrições específicas e pela comparação com os espécimes 
pertencentes à coleçāo do Museu Nacional do Rio de Janeiro. Em caso de dúvida, era solicitada a colaboração pessoal do Prof. Hugo de Souza Lopes.

O cálculo do índice de sinantropia foi realizado através da fórmula proposta por Nuorteva (1963), que é a seguinte:

$$
\text { IS }=\frac{2 a+b-2 c}{2} \text {, onde: }
$$

a - representa a porcentagem de determinada espécie capturada na área urbana, em relação a esta mesma espécie capturada na área de mata e na área rural;

b -.- representa a porcentagem da mesma espécie capturada na área rural;

c -- representa a porcentagem da mesma espécie capturada na área de mata.

O índice de sinantropia varia de +100 a -100 ; o primeiro valor representa o mais alto grau de sinantropia, enquanto valores negativos indicam aversão ao ambiente humano, em graus variáveis até o limite máximo de -100 .

\section{RESULTADOS}

Durante os doze meses de trabalho (maio de 1980 a abril de 1981) foram capturados 10.097 exemplares de Sarcophagidae, assim distribuídos:

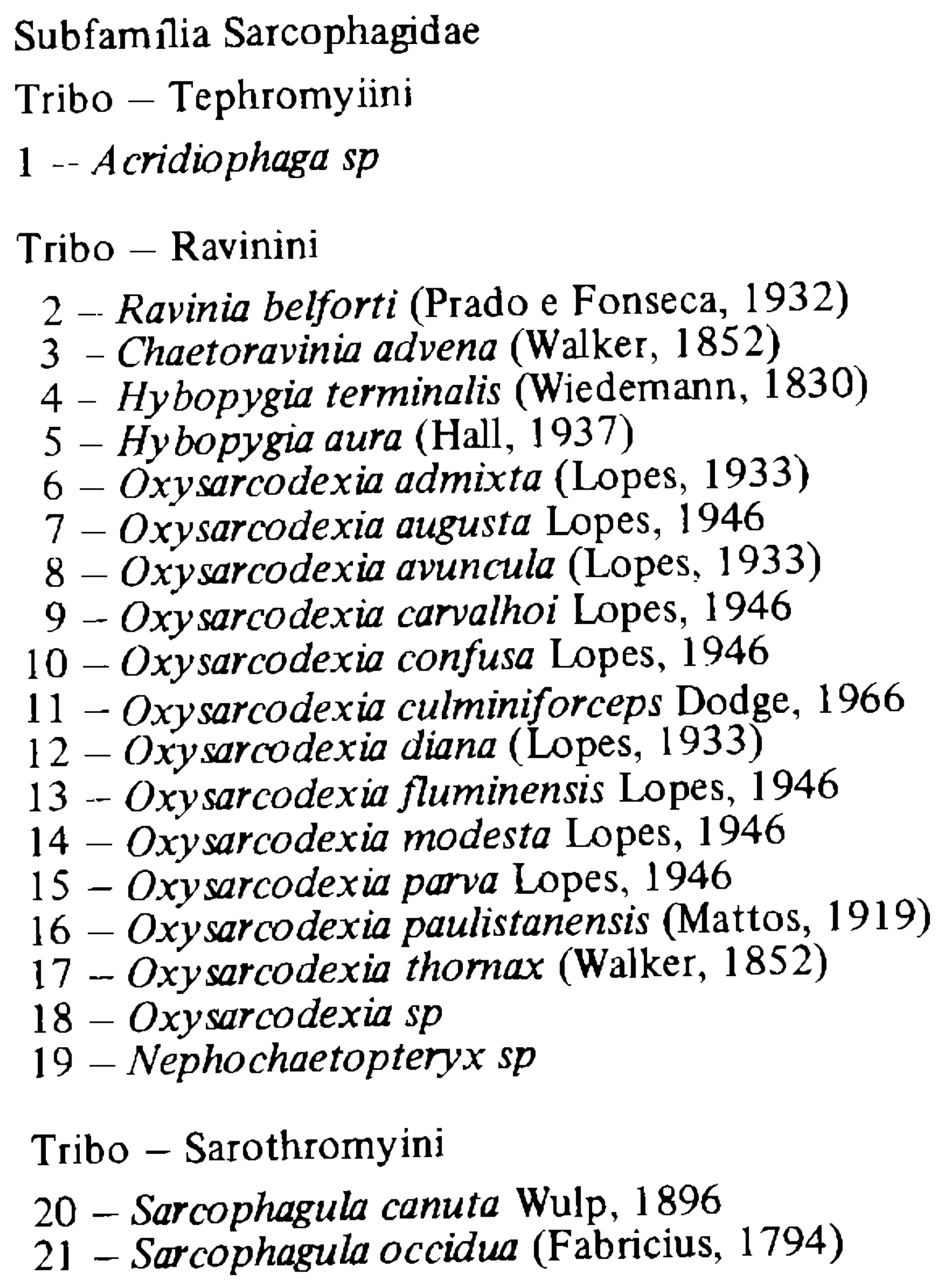

* Esta distribuição taxonômica foi feita de acordo com o novo catálogo de Lopes (comunicação pessoal) a ser publicado brevemente. 


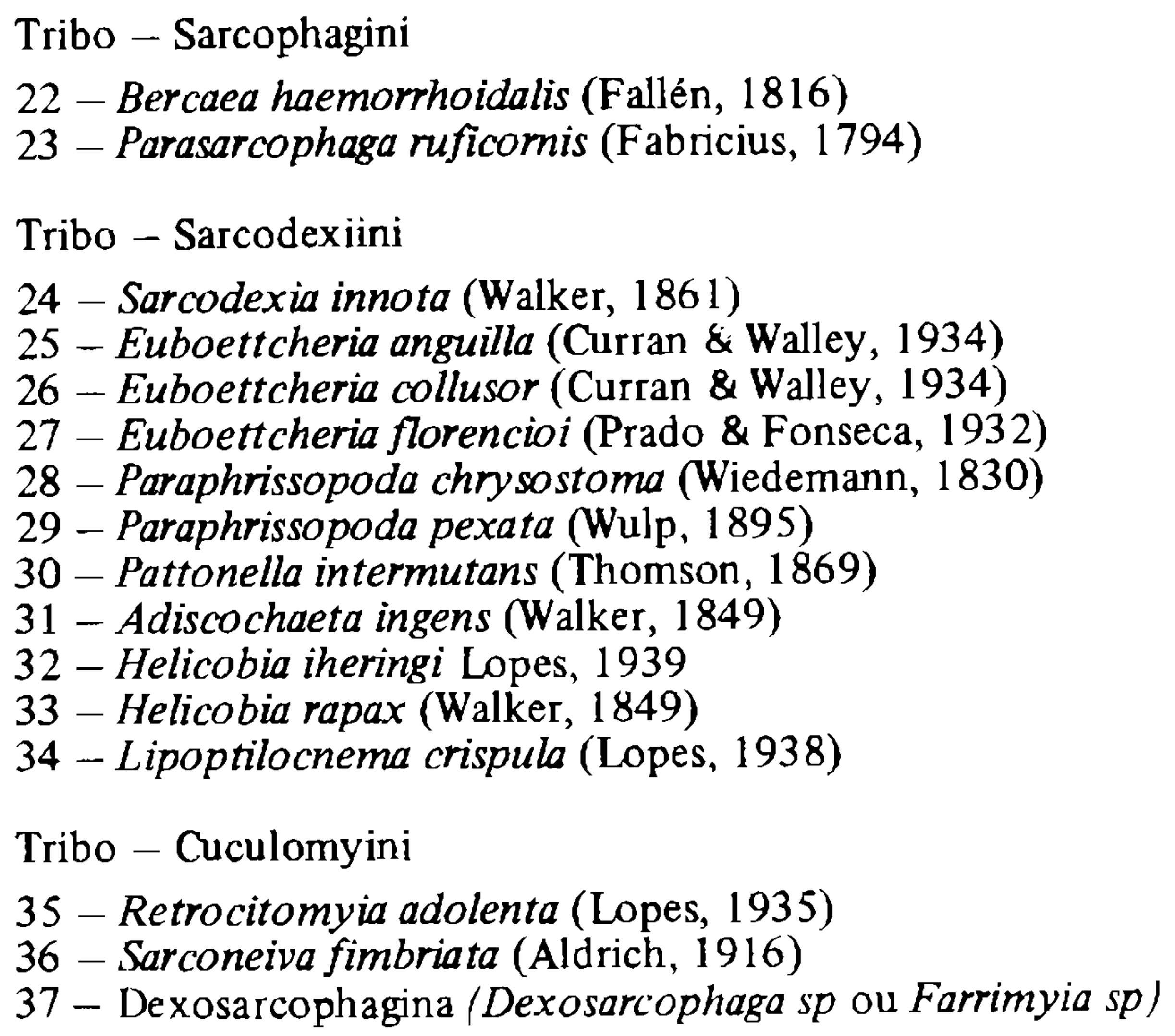

Dos exemplares capturados foram analisados 9.582 espécimes. Os demais (515 exemplares) nāo foram computados, uma vez que representaram espécies pouco numerosas e/ou que nāo se conseguiu chegar ao diagnóstico específico.

A Tabela I mostra os números absolutos e relativos de cada espécie capturada, em cada uma das áreas estudadas, e seus respectivos índices de sinantropia. Na Fig. 1 a freqüência relativa de cada espécie por área está melhor representada, enquanto a Fig. 2 fornece o índice de sinantropia de cada espécie e sua relação com o ambiente humano. Em nosso trabalho $P$. ruficornis $($ IS $=+94,7)$ e $B$. haemorrhoidalis $($ IS $=+94,3)$ foram as espécies mais sinantrópicas, enquanto $E$. florencioi $($ IS $=-98,8)$ e O. augusta $($ IS $=-96,9)$ foram as espécies que demonstraram maior aversão ao ambiente humano.

\section{DISCUSSÃO}

De acordo com os resultados pode-se verificar que a família Sarcophagidae contribuiu com um grande número de espécies na regiāo. Dos 9.582 espécimes analisados, $56,9 \%$ pertence ao gênero Oxysarcodexia, que segundo Lopes $(1946,1973$ e 1975) é caracteristicamente neotrópico e dominante no sul do Brasil, onde apresenta maior número de espécies do que qualquer ou tro gênero da família.

A espécie dominante no trabalho foi $O$. thornax com $23,1 \%$ dos 9.582 espécimes analisados. Demonstrou uma preferência por áreas desabitadas. A al ta freqüência desta espécie foi também observada por Ferreira (1978) em Curitiba. Linhares (1979) também chamou a atenção tanto quanto ao grande número de exemplares capturados, como tam. bém pela alta freqüência nas capturas com fezes humanas, em Campinas, sendo uma espécie hemissinantrópica e comunicativa naquela regiāo.

$P$. ruficornis foi a espécie mais sinantrópica, ocorrendo quase que exclusivamente na área urbana $(89,4 \%)$. Em Belo Horizonte seu índice de sinantropia foi de $+94,7$, o que demonstra sua adaptação ao ambiente humano. Esta observação passa a ter importância na medida em que esta espécie não é originária da região neotropical e sim importada da regiāo oriental, segundo Lopes (1973). Em Campinas, Linhares (1979) verificou também um al to índice de sinantropia para esta espécie $(+94,1)$. Este mesmo autor verificou ainda a presença de fêmeas grávidas, que penetravam no interior dos laboratórios do Departa- 


\section{TABELA I}

Freqüência absoluta e relativa de cada espécie de sarcophagidae, em cada área de captura e seus respectivos índices de sinantropia. Período de captura: maio de 1980 a abril de 1981, em Belo Horizonte, MG.

\begin{tabular}{|c|c|c|c|c|c|c|c|c|}
\hline \multirow[b]{2}{*}{ Espécies } & \multicolumn{2}{|c|}{ Urbana } & \multicolumn{2}{|c|}{ Rural } & \multicolumn{2}{|c|}{ Mata } & \multirow{2}{*}{ Total } & \multirow{2}{*}{ IS } \\
\hline & $N$ & $\%$ & $N ?$ & $\%$ & $N ?$ & $\%$ & & \\
\hline B. haemorrhoidalis & 267 & 85,9 & 26 & 8,4 & 18 & 5,8 & 311 & $+84,3$ \\
\hline C. advena & 4 & 3,2 & 42 & 33,3 & 80 & 63,5 & 126 & $-43,6$ \\
\hline E. anguilla & 5 & 5,3 & 8 & 8,4 & 82 & 86,3 & 95 & $-76,8$ \\
\hline E. collusor & 3 & 2,8 & 1 & 0,9 & 102 & 96,2 & 106 & $-93,0$ \\
\hline E. florencioi & - & - & 3 & 0,8 & 367 & 99,2 & 370 & $-98,8$ \\
\hline H. rapax & 9 & 14,1 & 42 & 65,6 & 13 & 20,3 & 64 & $+26,6$ \\
\hline H. terminalis & 241 & 36,5 & 339 & 51,4 & 80 & 12,1 & 660 & $+50,1$ \\
\hline L. crispula & 45 & 42,9 & 16 & 15,2 & 44 & 41,9 & 105 & $+8,6$ \\
\hline O. admixta & 63 & 15,9 & 7 & 1,8 & 327 & 82,4 & 397 & $-65,6$ \\
\hline$O$. augusta & - & - & 1 & 2,1 & 46 & 97,9 & 47 & $-96,9$ \\
\hline O. avuncula & 2 & 2,7 & 10 & 13,5 & 62 & 83,8 & 74 & $-79,4$ \\
\hline O. carvalhoi & - & - & 1 & 4,8 & 20 & 95,2 & 21 & $-92,8$ \\
\hline O. confusa & 18 & 6,8 & 13 & 4,9 & 232 & 88,2 & 263 & $-79,0$ \\
\hline O. culminiforceps & - & - & 9 & 40,9 & 13 & 59,1 & 22 & $-38,7$ \\
\hline O. diana & - & - & 54 & 8,8 & 559 & 91,2 & 613 & $-86,8$ \\
\hline O. modesta & 6 & 2,3 & 195 & 74,7 & 60 & 23,0 & 261 & $+16,7$ \\
\hline O. parva & 6 & 6,4 & 6 & 6,4 & 82 & 87,2 & 94 & $-77,6$ \\
\hline O. paulistanensis & 428 & 29,5 & 690 & 47,6 & 333 & 22,9 & 1451 & $+30,4$ \\
\hline O. thornax & 136 & 6,2 & 725 & 32,8 & 1349 & 61,0 & 2210 & $-38,4$ \\
\hline P. chrysostoma & 22 & 14,1 & 41 & 26,3 & 93 & 59,6 & 156 & $-32,4$ \\
\hline P. pexata & 1 & 1,5 & 13 & 19,1 & 54 & 79,4 & 68 & $-68,4$ \\
\hline P. ruficornis & 59 & 89,4 & 7 & 10,6 & - & - & 66 & $+94,7$ \\
\hline$P$. intermutans & 182 & 40,3 & 71 & 15,7 & 199 & 44,0 & 452 & $+4,2$ \\
\hline$R$. berforti & 94 & 34,6 & 103 & 37,9 & 75 & 27,6 & 272 & $+26,0$ \\
\hline S. innota & 345 & 27,0 & 175 & 13,7 & 758 & 59,3 & 1278 & $-25,5$ \\
\hline Atar & 1936 & & 2598 & & 5048 & & 9582 & \\
\hline
\end{tabular}

mento de Parasitologia da UNICAMP, indo larvipor em ração fermentada, carcaça de camundongo e lixo. Bohart \& Gressitt (1951) observando o comportamento desta espécie em Guam (ilha do Pacífico) verificaram também sua capacidade de endofilia, ou seja, penetração nas residências. Estes mesmos autores apontam esta espécie como transmissora de organismos patogênicos para o homem e, além disso, suas larvas podem causar miíases nos animais.

Outra espécie bastante sinantrópica foi $B$. haemorrhoidalis que apresentou um índice de sinantropia de $+84,3$, demonstrando sua preferência por áreas habitadas. Dado semelhante foi obtido por Linhares (1979) em Campinas, onde B. haemorrhoidalis foi o 


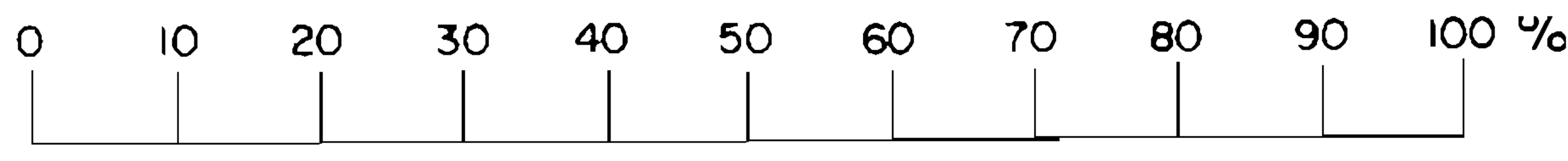

Bercoeo hoemorrhoidalis

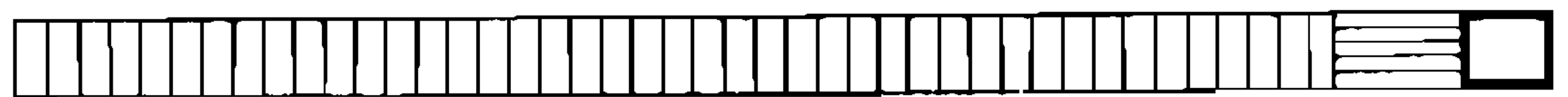

Choetoravinia adveno

Euboettcherio anguillo

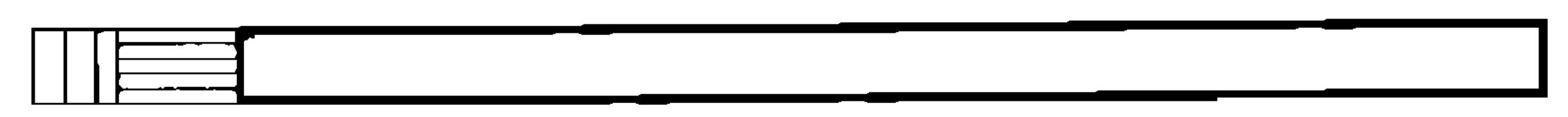

Euboettcheria collusor

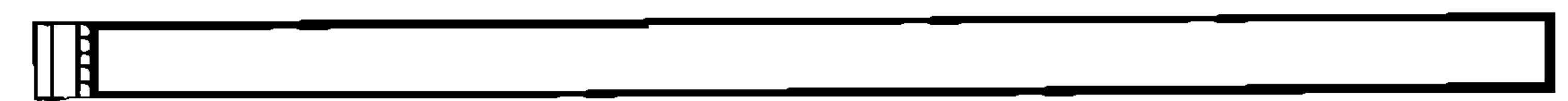

Euboettcheria florenciol

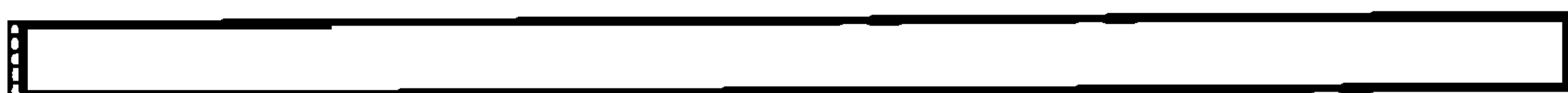

Helicobia rapax

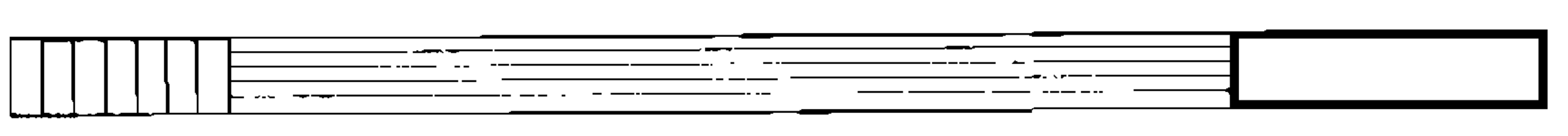

Hybopygia terminalis

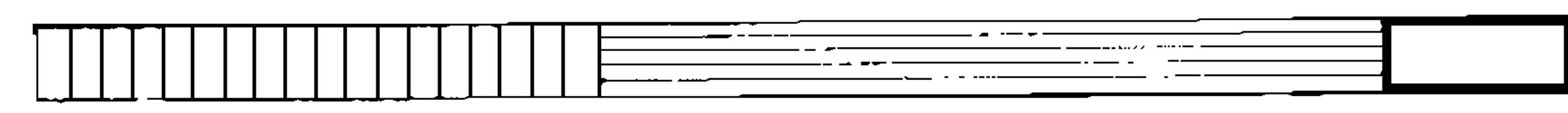

Lipoptilocnema crispula

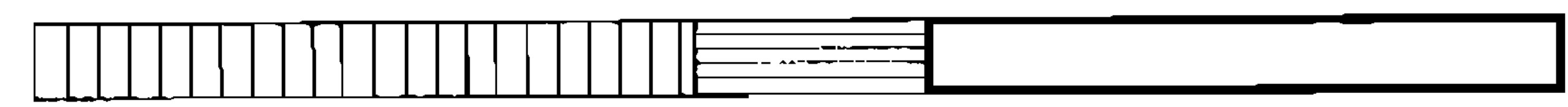

Oxysarcodexio admixto

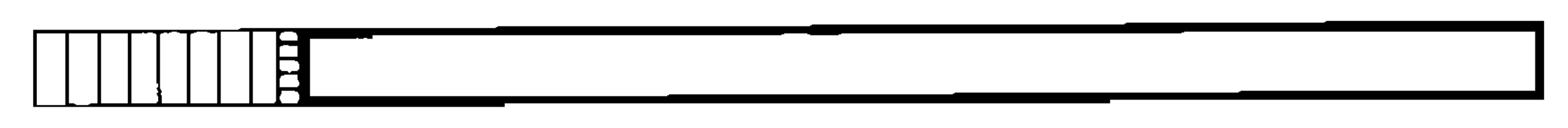

Oxysarcodexia augusto

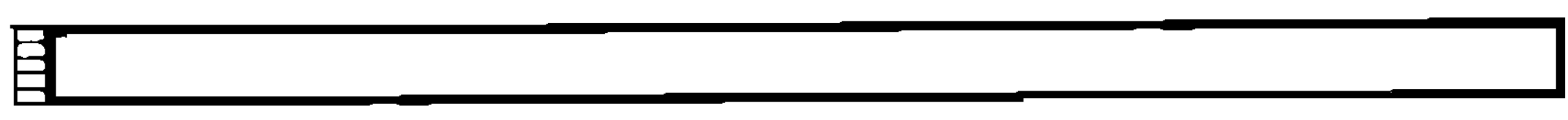

Oxysarcodexio avuncula

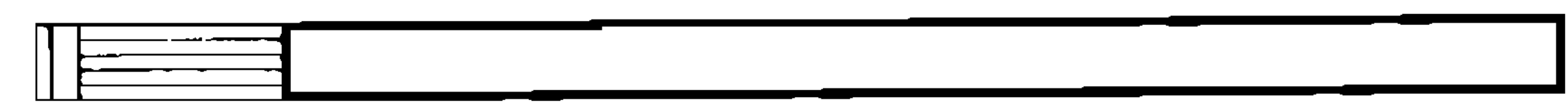

Oxysarcodexia carvalhoi

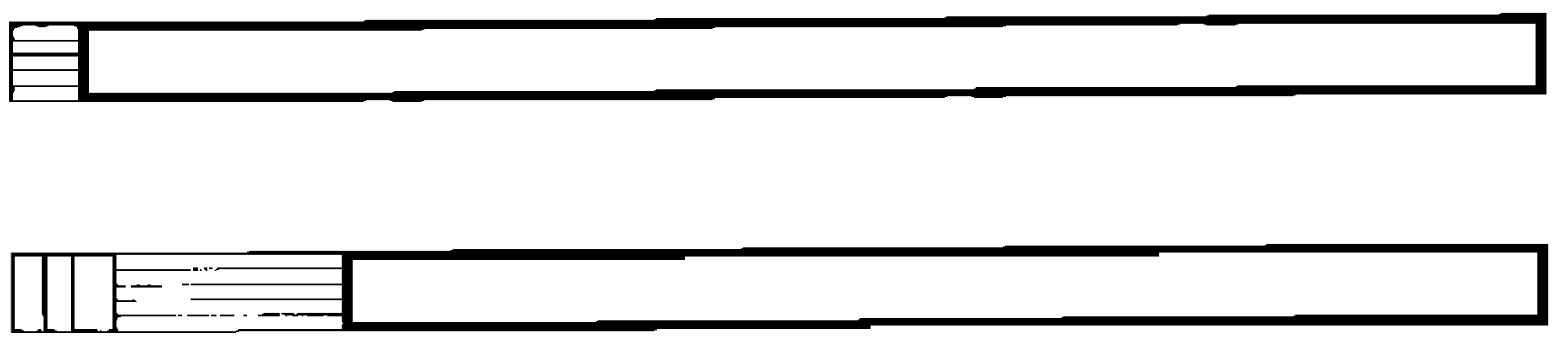

Oxysarcodexia confusa

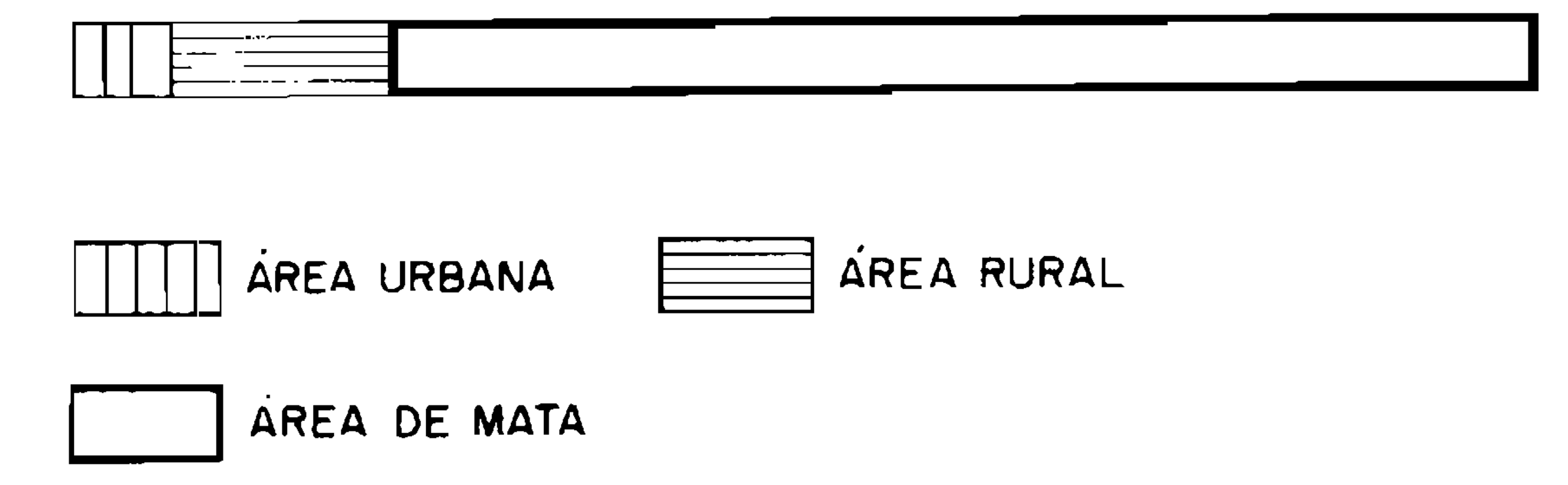

Fig. 1 - Freqüência relativa de cada espécie de Sarcophagidae em cada área de captura (urbana, rural e mata), no período de maio de 1980 a abril de 1981, em Belo Horizonte, MG (continua). 


\section{Oxysarcodexia culminiforceps}

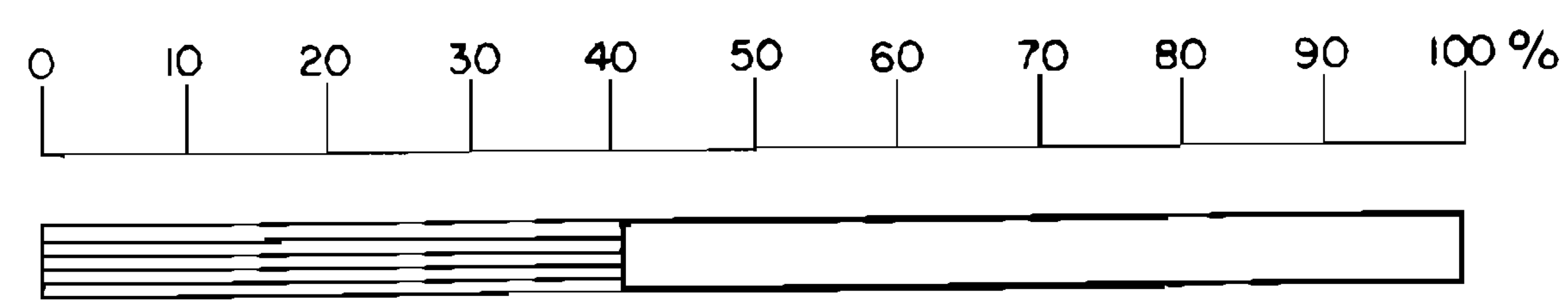

Oxysarcodexia diana

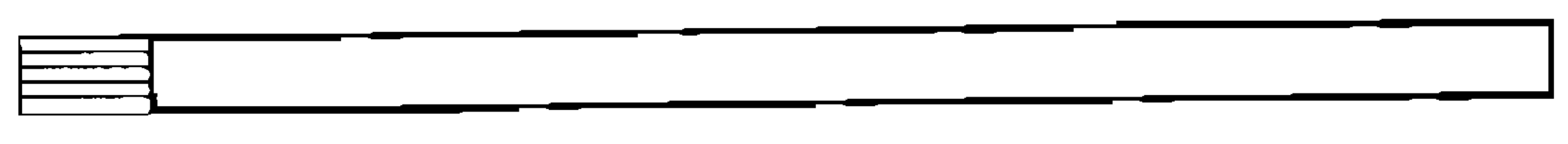

Oxysarcodexia modesta

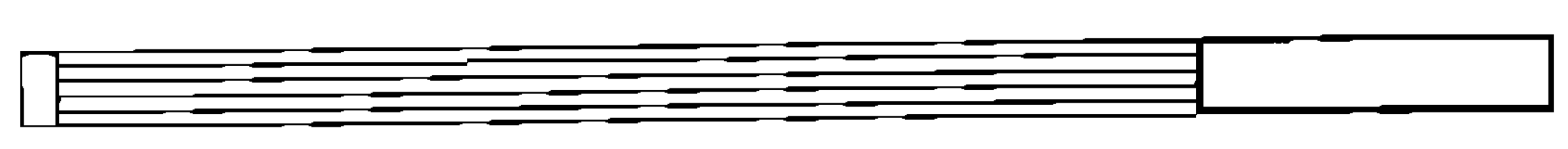

Oxysarcodexio parva

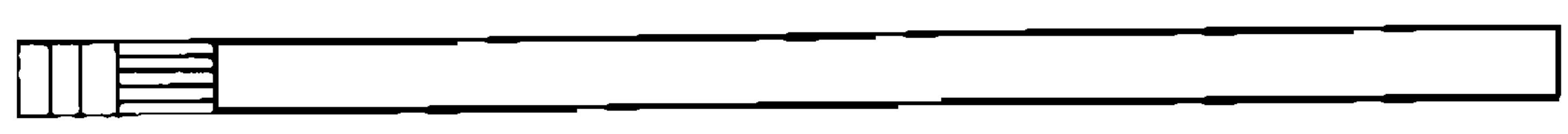

Oxysarcodexia paulistanensis

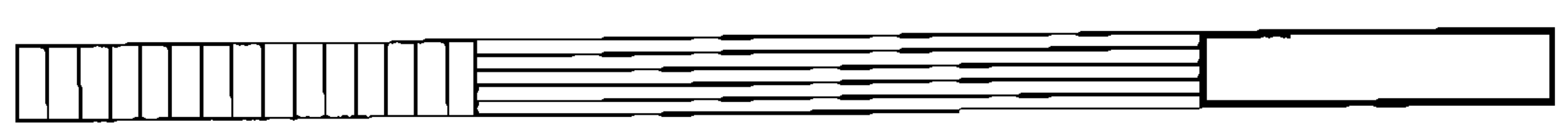

Oxysarcodexia thornax

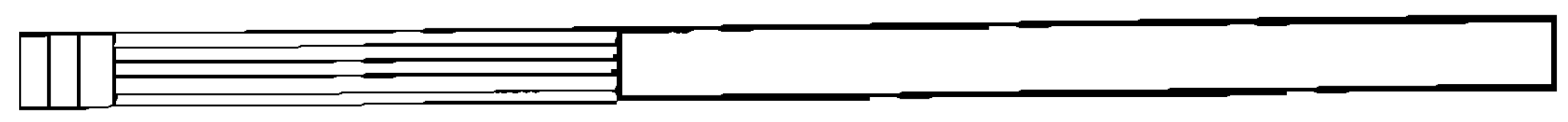

Poraphrissopoda chrysostoma

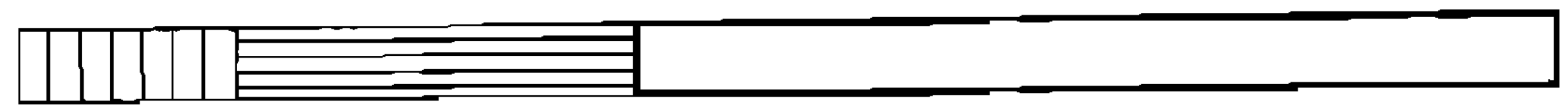

Paraphrissopoda pexata

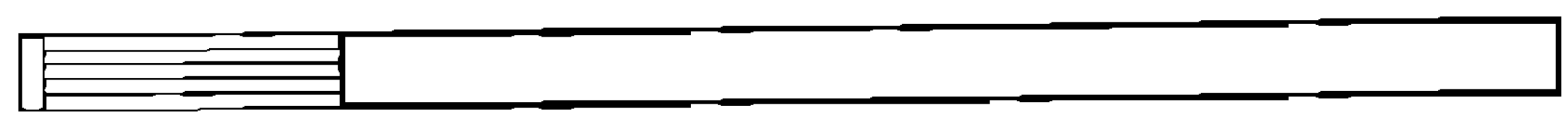

Parasarcophaga ruficornis

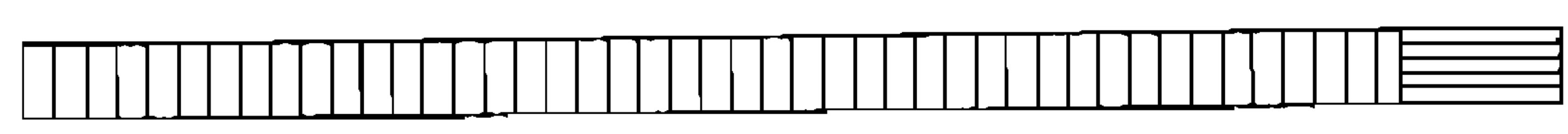

Pattonello intermutans

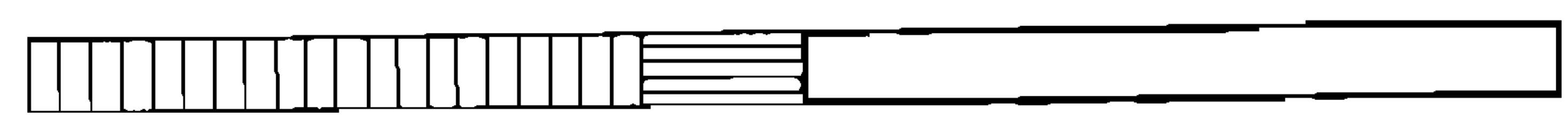

Rovinio belforti

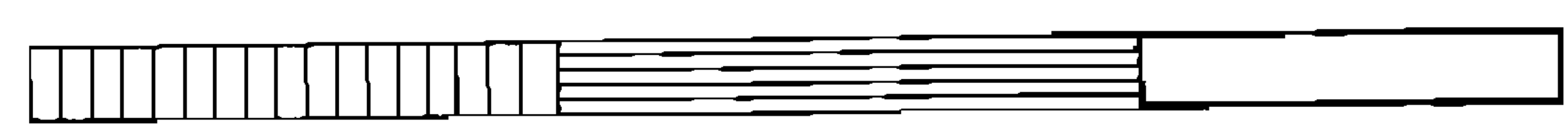

Sarcodexia innoto
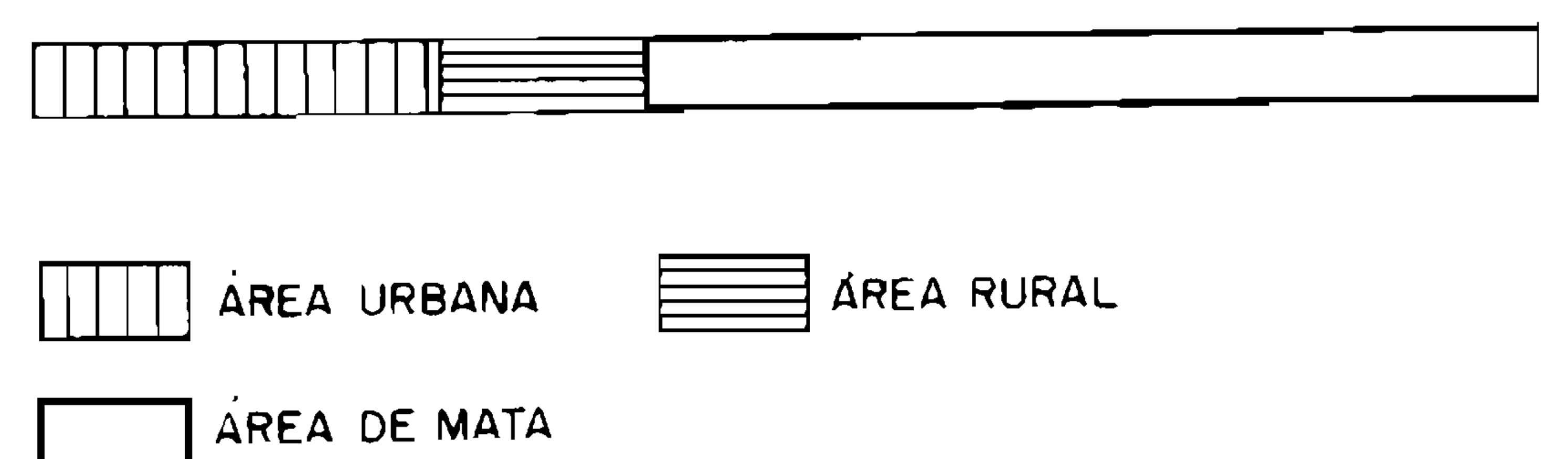

Fig. 1 - Frequência relativa de cada espécie de Sarcophagidae em cada área de captura (urbana, rural e mata), no período de maio de 1980 a abril de 1981, em Belo Horizonte, MG.

díptero mais sinantrópico dentre todos os estudados (IS $=+94,3)$. Sua preferência em áreas urbanas foi também observada por Iwuala e Onieka (1977), na Nigéria, Schoof \& Savage (1955) e Williams (1954), em Nova York.

Para Povolny \& Stanek (1972), em um levantamento realizado na Tchecoslováquia, B. haemorrhoidalis foi distintamente coprófaga, sendo a mais termófila de todas as espécies capturadas e ocorrendo com freqüência no ambiente urbano. De acordo com estes autores esta espécie ocorre no Novo Mundo, onde é largamente distribuída bem como na África (possível região de origem) possuindo forte tendência para a sinantropia. Aradi \& Mihályi (1971), estudando a fauna de moscas em mercados abertos em Budapest, verificaram que $B$. haemorrhoidalis foi a espécie mais numerosa dentre os sarcofagídeos capturados. Segundo James (1947), Zump (Apud Linhares, 1979) e Pessôa \& Martins (1982) esta espécie pode causar miíases no homem e outros animais. 


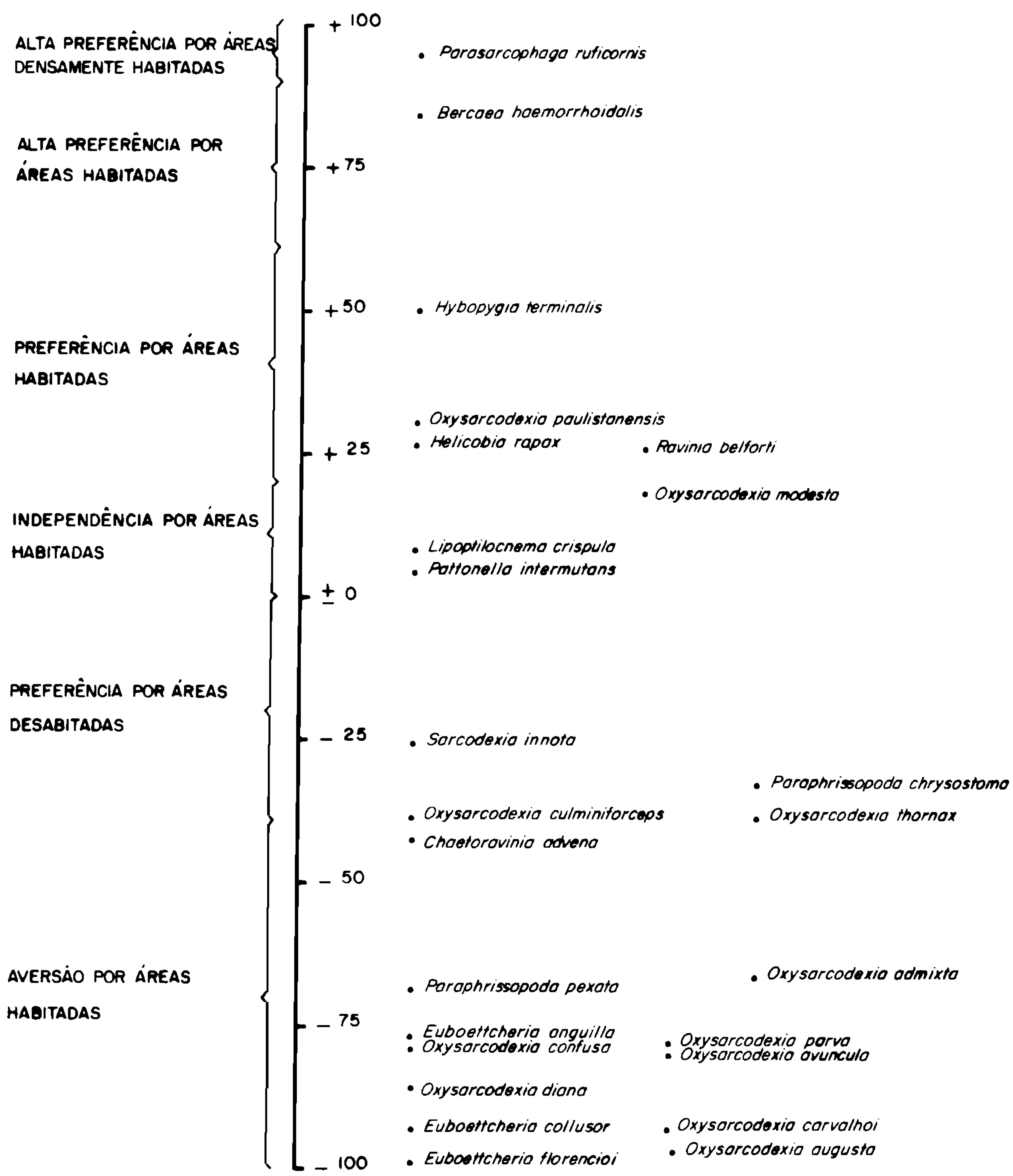

Fig. 2 - Ilustração dos diferentes graus de índices de sinantropia e a respectiva situação das espécies de Sarcophagidae em Belo Horizonte. Período de captura: maio de 1980 a abril de 1981.

As espécies mais assinantrópicas em nossa região foram $E$. florencioi, $O$. augusta, $O$. carvalhoi, E. collusor, que demonstraram aversão por áreas habitadas, como pode ser notado por seus índices extremos ( próximos de IS $=-100$ ).

Todas as outras espécies que não foram comentadas particularmente apresentaram um comportamento sinantrópico intermediário, distribuindo-se entre os vários graus de sinantropia na escala proposta por Nuorteva (1963), como pode ser visto na Fig. 1.

$\mathrm{O}$ índice de sinantropia está sujeito à influência de vários fatores característicos de cada região, como relevo, vegetação, clima e altitude. Além disso existe também a influência das áreas escolhidas para captura. Apesar destes comentários, os índices sinan- 
trópicos obtidos por este método contribuem para a compreensão do comportamento das espécies de sarcofagídeos e outros dípteros muscóides.

\section{SUMMARY}

Over a period of one year (May, 1980 to April, 1981), systematic collections of Sarcophagidae were made in three ecologically distinct areas of Belo Horizonte, Minas Gerais. Two types of traps and five types of bait were used: raw fish, carcasses of mice, viscera of chickens, banana mashed with sugar, and human faeces. Of the total of 10,097 specimens captured, the 9,582 studied included 25 species. Indices of synanthropy (I.S.) for the 25 species varied considerably. The most synanthropic were Parasarcophaga ruficornis (I.S. $=+94.7$ ) and Bercaea haemorrhoidalis (I.S. $=+84.3)$, and the least were Euboettcheria florencioi (I.S. $=-98.8)$ and Oxysarcodexia augusta $($ I.S. $=-96.9)$.

\section{REFERẼNCIAS BIBLIOGRÁFICAS}

ARADI, M.P. \& MIHẢLYI, F., 1971. Seasonal investigations of flies visiting food markets in Budapest. Acto Zool. Acad. Sci. Hung., $17: 1 \cdot 10$.

BOHART, G.E. \& GRESSITT, J.L., 1951. Filth - inhabiting flies of Guam. Bull. Berenice P. Bishop Mus. (204) : 1-152.

FERReirA, M.J.M., 1978. Sinantropia de dípteros muscóides de Curitiba, Paraná. I. Calliphoridae. Rev. Brasil. Biol., $38: 445-54$.

FERREIRA, M.J.M., 1979. Sinantropia de dípteros muscóides em Curitiba, Paraná. II. Sarcophagidae. Rev. Brasil. Biol., $39(4): 773-81$.

IWUALA, M.O.E. \& ONYEKA, J.O.A., 1977. The type and distribution patterns of domestic flies in Nsukka, East Central State, Nigeria. Environ. Entomol., $6: 43-9$.

JAMES, M.T., 1947. The flies that causes myiasis in man. U.S. Dep. Agric. Misc. Publ. (631) :1-175.

LINHARES, A.X., 1979. Sinantropia de dípteros muscóides de Campinas, Campinas, UNICAMP, 129p. Tese de Mestrado.

LINHARES, A.X., 1981. Synanthropy of Calliphoridae and Sarcophagidae (Diptera) in the city of Campinas, São Paulo, Brasil. Rev. Brasil. Biol., 25 (3) :189-215.

LOPES, H.S., 1946. Contribuiçāo ao conhecimento do gênero Oxysarcodexia Townsendi, 1917 (Diptera, Sarcophagidae). Bol. Esc. Nac. Vet., 1 :62-134.

LOPES, H.S., 1973. Collecting and rearing Sarcophagid flies (Diptera) in Brasil during forty years. $A \boldsymbol{n}$. Acad. Bras. Cienc., $45(2): 279-91$.

LOPES, H.S., 1975. New or little known Oxysarcodexia (Diptera, Sarcophagidae). Rev. Brasil. Biol., $35(3): 461-83$.

NUORTEVA, P., 1963. Synanthropy of blowflies (Dipt., Calliphoridae) in Finland. Ann. Entomol. Fenn., $29: 1-40$.

PESSŌA, S.B. \& MARTINS, A.V., 1982. Parasiotologia Médica. 11 ed. Rio de Janeiro, Guanabara Koogan, 872p.

POVOLNY, D. \& STANEK, M., 1972. Diptera of the family Sarcophagidae as a component of the European synusia of synanthropic flies. Acta Univ. Agric., XX (3) :463-477.

SCHOOI; H.F. \& SAVAGE, E.P., 1955. Comparative studies of urban fly populations in Arizona, Kansas, Michigan, New York and West Virginia. Ann. Entomol. Soc. Am., 48:1-12.

WILLIAMS, R.W., 1954. A study of the filth flies in New York City. J. Econ. Entomol., 47 :556-63.

ZL'MPT, F., 1965. Mysiasis in animals and man, 267pp. London. Apud: LINHARES, A.X. Sinantropia de dipteros muscóides de Campinas. Campinas, UNICAMP, 1979p. Tese de Mestrado. 